REVESCO. Revista de Estudios Cooperativos ISSN: $1885-8031$

http://dx.doi.org/10.5209/REVE.63561

\title{
Evaluar y promover las competencias para el emprendimiento social en las asignaturas universitarias
}

Leticia Concepción Velasco Martínez ${ }^{1}$, Ligia Isabel Estrada Vidal², Manuela Pabón Figueras $^{3}$ y Juan Carlos Tójar Hurtado ${ }^{4}$

Recibido: 2 de julio de 2018 / Aceptado: 28 de enero de 2019

Resumen. Las universidades, así como diversas entidades científicas y académicas, tanto a nivel nacional como internacional, han tomado conciencia de la necesidad de promover el emprendimiento en el ámbito universitario (UNESCO, 2009; Guerrero, Urbano, Ramos, Ruiz-Navarro, Neira y Fernández-Laviada, 2016). En este trabajo se presenta una herramienta que resulta útil para evaluar las competencias para el emprendimiento social en cualquier asignatura universitaria. Se han realizado dos versiones de la herramienta (estudiantes y profesorado) que permiten analizar y valorar el grado en que dichas competencias se trabajan en una asignatura concreta. Además, la versión del docente está diseñada para promover la reflexión en el profesorado sobre el margen de mejora de las competencias emprendedoras y favorecer la puesta en práctica de propuestas concretas para integrarlas en las asignaturas a corto plazo. La herramienta, en sus dos versiones, denominada "Registro para Evaluar el Emprendimiento Social en las Aulas Universitarias (RESAU)", ha sido validada por 14 expertos. En la versión de estudiantes se realizó una validación estadística empleándose una muestra piloto de estudiantes de Ciencias Económicas y de Ciencias de la Educación $(n=180)$, de las Universidades de Granada, Málaga y Sevilla. En el caso de la versión de los estudiantes, la herramienta muestra en qué medida las competencias para el emprendimiento social se trabajan en las actividades de aula. En la versión del profesorado, la herramienta ilustra adecuadamente aquellas competencias para el emprendimiento social que son trabajadas en cada asignatura, y las que poseen un margen de mejora que puede ser desarrollado por cada docente universitario. Las conclusiones del estudio destacan la relevancia de trabajar las competencias para el emprendimiento social en las aulas universitarias y ponen de relieve la manera en que cada docente plantea estrategias de mejora.

Palabras clave: Emprendedor social; Instrumento; Competencia; Percepción; Asignatura; Universidad.

Claves Econlit: I20; I23; A13; L26.

1 Universidad de Málaga, España

Dirección de correo electrónico: leticiav@uma.es

2 Universidad de Granada, España

Dirección de correo electrónico: ligia@ugr.es

3 Universidad de Sevilla, España

Dirección de correo electrónico: mpabon1@us.es

$4 \quad$ Universidad de Málaga, España

Dirección de correo electrónico: jctojar@uma.es 
[en] Evaluating and promoting competencies for social entrepreneurship in university subjects

\begin{abstract}
Universities, as well as several scientific and academic entities, both nationally and internationally, have become aware of the need to promote entrepreneurship in the university sphere (UNESCO, 2009; Guerrero, Urbano, Ramos, Ruiz-Navarro, Neira y Fernández-Laviada, 2016). This paper presents a tool that is useful for evaluating the skills for social entrepreneurship in any university subject. Two versions of the tool have been made (students and educators) that allow analysing and assessing the degree to which these competences are worked on in a specific subject. In addition, the educator's version is designed to promote reflection in the faculty on the margin of improvement of each of the entrepreneurial skills and encourage the implementation of concrete proposals to integrate them into short-term subjects. The tool, in its two versions, named "Register to Evaluate Social Entrepreneurship in the University Classrooms" (RESAU), has been validated by 14 experts. In the case of the student version, a statistical validation has been carried out in the a pilot sample of students of Economic Sciences and Educational Sciences $(n=180)$, from the universities of Granada, Malaga and Seville. In the case of the students' version, the tool shows to what extent the competences for social entrepreneurship are worked on in the classroom activities. In the educator's version, the tool adequately illustrates those competencies for social entrepreneurship that are worked on in each subject and those that have a margin of improvement that can be developed by each educator. The conclusions of the work highlight the relevance of working skills for social entrepreneurship in university classrooms and highlight the way in which each educator proposes improvement strategies.
\end{abstract}

Keywords: Social enterpriser; Tool; Competencie; Perception; Subject; University.

Sumario. 1. Introducción. 2. Objetivos 3. Metodología. 4. Resultados. 5. Conclusiones. 6. Referencias bibliográficas.

Cómo citar: Velasco Martínez, L.C., Estrada Vidal, L.I., Pabón Figueras, M. y Tójar Hurtado, J.C. (2019) Evaluar y promover las competencias para el emprendimiento social en las asignaturas universitarias. REVESCO. Revista de Estudios Cooperativos, Segundo Cuatrimestre, Nº 131, pp. 199223. DOI: 10.5209/REVE.63561.

\title{
1. Introducción
}

Las universidades, así como diversas entidades científicas y académicas, tanto a nivel nacional como internacional, han tomado conciencia de la necesidad de promover el emprendimiento en el ámbito universitario (UNESCO, 2009; Guerrero, Urbano, Ramos, Ruiz-Navarro, Neira y Fernández-Laviada, 2016). De hecho, uno de los indicadores de calidad que propone la UNESCO es la capacidad que tienen las universidades para preparar al alumnado en la adquisición de conocimientos, habilidades y actitudes para dar respuesta a las demandas del mercado laboral actual (Espíritu, González y Alcaraz, 2012).

Por consiguiente, uno de los retos de la Educación Superior, es atender a las necesidades generadas por los cambios que se están produciendo en nuestra sociedad. De este modo, resulta esencial proporcionar al alumnado un desarrollo integral en su formación, capacitándoles para afrontar los retos y adversidades que surgen en el ejercicio de la profesión. También, formarlos para superar las presiones y altas demandas del puesto de trabajo, exige al alumnado salir de su zona de confort e ir más allá de su individualidad, mejorando su sentido de la responsabilidad social y la conciencia colectiva. Todo ello, favorece la capacidad 
del alumnado para participar activamente dentro de una sociedad democrática, siguiendo los principios de igualdad y justicia (Espíritu et al., 2012; Sáenz y López, 2015; Sigüenza, Macías y Serrano, 2016).

En este sentido, Salinas y Osorio (2012) señalan que la Universidad es un semillero de emprendedores, que aporta formación, orientación y acompañamiento a los estudiantes para que pongan sus conocimientos, competencias y herramientas al servicio de la sociedad.

Los antecedentes encontrados en la literatura sobre emprendimiento social, coinciden en destacar que abarca dos conceptos claves: emprendedor y empresa social. El primer término hace alusión a aquella persona que innova a partir de creaciones nuevas, siendo agente de cambio para la sociedad y al mismo tiempo mejora el sistema existente mediante la adaptación de recursos. Respecto al segundo, a pesar de existir discrepancias en su definición, una empresa social hace referencia a características propias de una entidad de mercado y de una organización no gubernamental, cuyos objetivos son principalmente sociales, dirigiendo sus prioridades a la creación y mantenimiento de puestos de trabajo, a la vez que presta servicios a las comunidades locales. Así, los beneficios se invierten al propio negocio o la comunidad, en lugar de ser a los propietarios o los accionistas (Wronka-Pospiech, 2016), donde entra en juego la toma de decisiones, el capital humano y el capital social a nivel individual (Jiao, 2011). Todo ello, implica establecer un alto grado de flexibilidad, que permita alcanzar los objetivos económicos y sociales al mismo tiempo (Wronka-Pospiech, 2016). De este modo, se puede indicar que el emprendimiento es la intersección que existe en la concurrencia entre la perspectiva teórica económica, psicológica y sociológica. De esta manera, influyen aspectos como los comportamientos económicos de los empresarios, sus motivaciones, actitudes, valores o procesos cognitivos, entre otros, implicados en la toma de decisiones dirigidas a la elección y desarrollo del empleo, así como del autoempleo (Sánchez, Ward, Hernández y Florez, 2017).

En esta línea, nadie duda sobre la relevancia de la educación para el desarrollo del emprendimiento y la economía social, puesto que estas mejoran con la competencia de mercado más eficiente, la solidaridad, la cohesión, un alto grado de flexibilidad, así como de innovación, favoreciendo así, competencias que facilitan una rápida y adecuada adaptación al contexto socio-económico (Mateescu, 2014).

Por consiguiente, a través de la educación para el emprendimiento social en el ámbito universitario, se promueve el desarrollo a nivel individual de los aspectos enunciados anteriormente, permitiendo a los futuros profesionales generar soluciones innovadoras a los problemas sociales (resolución de problemas), convirtiéndose la educación en una herramienta de cambio y transformación social.

De forma más concreta, puede favorecer el desarrollo de capacidades para crear un negocio social, apoyado en la creatividad, la autosuficiencia, el pensamiento racional, la empatía y las habilidades empresariales del alumnado, contribuyendo así, al desarrollo de una economía sostenible. Por ello, surge la necesidad de generar modelos educativos con una estructura de aprendizaje holístico que desarrolle aprendizajes cognitivos, conductuales y afectivos (Glunk y Van Gils, 2010).

En este sentido, debido a que las instituciones universitarias se fundamentan cada vez más en dichas ideas, se está extendiendo la educación e investigación de 
competencias para el emprendimiento social en el ámbito universitario (ÁlvarezSampayo, González-Díaz y Vergara-Gómez, 2016; Espíritu et al., 2012; Rojas, Quintero, Pertuz y Navarro, 2016).

El emprendimiento social y los valores que promueve (Seguí-Mas, TormoCarbó, Sarrión-Viñes y Julià-Igual, 2014), coinciden en gran medida con las competencias transversales que deben trabajarse en la Universidad (Blanco, Garín y Rodríguez-Jiménez, 2012; Sánchez et al., 2017). En este sentido, Guerrero et al. (2016), indican que las competencias transversales que contribuyen a la formación en emprendimiento suelen ser:

Instrumentales, como pueden ser la comunicación oral, toma de decisiones, resolución de problemas, o los conocimientos tecnológicos.

Interpersonales, como son el trabajo en equipo, creación de redes de contactos, cooperación y diálogo con otras personas, ética, o el compromiso y responsabilidad social.

Sistemáticas, como por ejemplo, la identificación de retos y oportunidades, diseñar nuevos productos/servicios, gestión, planificación, o la comercialización.

Por consiguiente, el enfoque por competencias, parece ser un modelo idóneo para enseñar y evaluar competencias referidas al emprendimiento social. Desde esta perspectiva, Sáenz y López (2015), destacan la importancia de crear un marco común de referencia para la formación en emprendimiento social. En este sentido, dichas autoras elaboraron una clasificación de competencias para fomentar el emprendimiento social, a través de una exhaustiva revisión de la literatura y un análisis de los planes de estudios de distintas universidades de América Latina y España. Esta clasificación consta de 4 bloques de competencias claves: 1) Competencias relacionadas con la tarea o trabajo a realizar (reconocimiento de oportunidades, delimitación de objetivos, toma de decisiones, etc.); 2) Competencias relativas a las relaciones sociales (liderazgo, trabajo en equipo, comunicación, etc.); 3) Competencias respecto al desarrollo de capacidades personales (adaptabilidades, perseverancia, capacidad de asumir riesgos, etc.); y 4) Competencia filosófica y ética (sentido ético, conciencia del otro, pensamiento crítico, etc.). Este último bloque, como señalan estas autoras, es "la marca de identidad" que caracteriza la persona emprendedora social (Sáenz y López, 2015:174).

En otro sentido, se destaca el modelo de educación para el emprendimiento social propuesto por Sinha, Pathak y Thomas (2014), cuyo máximo nivel es el $6^{\circ}$, correspondiente a la educación para el emprendimiento social, donde el alumnado compararía diversos sectores, participaría en proyectos de consultoría de emprendedores, o la redacción de informes, todo ello, para desarrollar la capacidad de resolución de problemáticas.

Considerando todo el engranaje necesario para la formación en emprendimiento social, el Informe sobre el Perfil Emprendedor del Estudiante Universitario, realizado por el Observatorio de Emprendimiento Universitario (Guerrero et al., 2016), resalta el papel tan relevante que tiene la Universidad en la configuración de "ecosistemas emprendedores". No solo aportando como un agente transformador sino también contribuyendo con la creación de entornos propicios para la 
generación de capital humano, la atracción de talento, y la generación de conocimiento, que puede ser transferible a la sociedad a través de iniciativas con un alto impacto social y económico.

Desde esta perspectiva, la Universidad apuesta por la innovación en todos los ámbitos, y la formación interdisciplinar que se ve fortalecida por el acuerdo, cada vez mayor, en la necesidad de originar nuevos modelos de empresas y de negocios orientados a resolver los problemas sociales que caracterizan a nuestro tiempo.

El nuevo modelo de Universidad que se promueve desde el proceso de Convergencia Europea intenta dar respuesta al complejo y heterogéneo contexto económico y social de nuestra sociedad actual. En este sentido, según Priede, López-Cózar y Rodríguez (2014), el emprendedor social es la persona que intenta dar respuesta a problemáticas referidas a la adquisición de una vivienda, la inclusión de colectivos vulnerables, la formación y la inserción sociolaboral, la gestión de la dependencia, etc., a través del desarrollo de ideas innovadoras, la inversión de recursos, esfuerzo y compromiso personal. Las iniciativas y propuestas de emprendimiento social que emanan de los objetivos y compromisos que tiene la Universidad, van dirigidas a establecer nuevas fórmulas empresariales más amplias y plurales que faciliten un desarrollo humano sostenible (Seguí-Mas, et al., 2014).

Los datos de emprendimiento social en España apoyan aún más esta tendencia de emprendimiento como salida laboral para los jóvenes, ya que un buen número de ellos-el 37\%- tienen entre 25 y 34 años. Además, un dato llamativo que señalan los autores del informe es el elevado porcentaje (comparado con el de los otros países industrializados), de emprendedores sociales con estudios medios o Formación Profesional. Sorprendentemente, el porcentaje de emprendedores sociales con estudios superiores es tan solo del 7,1\%.

En consecuencia, uno de los grandes retos de la Educación Superior para el siglo XXI es formar a estudiantes en el desarrollo de competencias para el emprendimiento social, que les permitan prevenir y resolver problemas sociocomunitarios, así como realizar acciones con fines sociales en su ámbito de actuación profesional futura.

En las instituciones de educación superior españolas a menudo se encuentran diversos recursos y estrategias formativas (seminarios, jornadas, programas, congresos, semilleros, talleres, clubes, espacio de incubación, concursos, premios, cátedras, laboratorios, becas, redes, etc.), que promueven el espíritu emprendedor entre los estudiantes (Dirección General de Industria y de la Pequeña y Mediana Empresa, 2012). No obstante, en lo referido a la introducción del emprendimiento social y la creación de empresas sostenibles en el currículo, existe aún una gran ausencia de oferta formativa, así como una carencia respecto a las estructuras de apoyo, promoción y fomento que permiten su desarrollo en las aulas universitarias (Bel, Durán, Fernández-Guadaño, Lejarriaga, y Martín-López, 2016; López-Cózar y Priede, 2014; Melián, Campos y Sanchis, 2017).

En este sentido, Viloria (2017), propone la necesidad de trabajar con el profesorado una serie de competencias que le faciliten la enseñanza sobre el emprendimiento para la innovación, en las que se incluyen competencias empresariales (iniciativa empresarial, capacidad de trabajo en equipo, y percepción de riesgos), actitudes y atributos (creatividad, responsabilidad social y liderazgo), y 
competencias tecnológicas. En esta línea, hay que destacar que ha proliferado la aparición de estudios dirigidos a identificar las necesidades académicas que influyen en el proceso de aprendizaje para desarrollar la capacitación del perfil emprendedor social de alumnado propio de titulaciones universitarias, en contextos donde ya se están introduciendo buenas prácticas dirigidas al aprendizaje de la creatividad y la innovación (Ferrer-Cerveró, Cabrera-Santacana, Alegre-Beneria, Montané-Lopez, Sánchez-Valverde y Alaiz-Chueca, 2014). A modo de ejemplo, hay países donde un alto porcentaje de alumnado no comprende que los estudiantes pueden llegar a ser figuras activas del emprendimiento social, generando un impacto social bajo un enfoque de actitud responsable hacia la comunidad (Peric y Delic, 2014).

Sin embargo, si bien es cierto que ha aumentado la demanda de educación en emprendimiento social en el contexto universitario, todavía es deficitario el conocimiento sobre aquellas competencias relacionadas con el éxito en el ámbito del emprendimiento social (Miller, Wesley y Williams, 2012; Wronka-Pospiech, 2016), entendiendo que el concepto de competencia abarca tanto los comportamientos que presenta una persona con los estándares mínimos de rendimiento establecidos (Mitchelmore y Rowley, 2010).

Entre las propuestas de futuras investigaciones, se recomienda incidir en el desarrollo de buenas prácticas educativas de emprendimiento social en el sistema universitario, la concienciación hacia el cambio del contexto económico-laboral, la inclusión de procesos de aprendizaje dirigidas al alumnado y el profesorado que les permita adquirir herramientas y habilidades para ello, la colaboración en red con entidades externas a la Universidad, así como el crear cultura emprendedora e intraemprendedora social universitaria como mejora social y económica (FerrerCerveró, et al., 2014). En definitiva, se destaca la necesidad de investigar más en dicha materia, especialmente la relacionada con la sostenibilidad, como oportunidad de renovación estratégica empresarial que, como consecuencia, repercute en la sociedad. Para ello, se necesita ahondar más en la concreción de entornos de aprendizaje que favorezcan y desarrollen competencias individuales (Mindt y Rieckmann, 2017).

Desde esta perspectiva, esta investigación trata de promover el compromiso de los docentes universitarios con el cambio, a partir de la indagación en sus modos de trabajo en relación a la inclusión del emprendimiento social. La investigación se enfoca en la práctica docente que se está desarrollando en las aulas de las universidades andaluzas y en su relación con las características asociadas del emprendimiento social en el currículo universitario. Los interrogantes principales que guían el proyecto se formulan en los siguientes términos:

¿Cómo son las prácticas docentes del profesorado universitario y de qué modo se reflejan en ellas criterios asociados al emprendimiento social en el currículo?

- ¿Qué márgenes de mejora existen para impulsar currículos coherentes con los principios del emprendimiento social y las propuestas de cambio educativo del Espacio Europeo?

¿Qué estrategias, procesos y recursos son necesarios para favorecer la integración y desarrollo de competencias para el emprendimiento social en cada una de las asignaturas implicadas en el proyecto? 
- ¿Cómo perciben los estudiantes el trabajo que realizan sus docentes en relación al emprendimiento social?

Teniendo presente que las cuestiones planteadas abarcan un amplio ámbito de investigación, y considerando que este trabajo supone una primera aproximación al campo del emprendimiento social en el currículo, el objetivo de esta investigación es realizar un diagnóstico de las prácticas docentes relacionadas con criterios de emprendimiento social, desarrolladas en varias asignaturas y titulaciones oficiales universitarias andaluzas. También analizar los márgenes de mejora en cada una de ellas, proponer iniciativas de integración y desarrollo de contenidos transversales desde la perspectiva del emprendimiento social $\mathrm{y}$, finalmente, evaluar la efectividad de su aplicación en la docencia en asignaturas universitarias.

\section{Objetivos}

El presente trabajo persigue el desarrollo futuro de acciones conjuntas a través de grupos de trabajo inter-universitario que impulsen el proceso de introducción de la cultura emprendedora en el currículum académico universitario, permitiendo la adquisición de competencias para el emprendimiento social y el empleo mediante la inclusión de competencias y contenidos básicos transversales. Esta investigación pretende fomentar que los estudiantes universitarios adquieran competencias básicas para tomar decisiones y realizar sus acciones profesionales desde una perspectiva social y hacia el compromiso y la responsabilidad social. Por ello, esta investigación se dirige a alcanzar los siguientes objetivos:

- Realizar un diagnóstico sobre el nivel inclusión de contenidos y competencias referidas al emprendimiento social, durante la docencia en diferentes asignaturas y titulaciones oficiales universitarias.

- Identificar y analizar los márgenes de mejora hacia el emprendimiento social en cada una de las asignaturas.

Analizar la percepción de los estudiantes respecto a la impartición y adquisición de competencias y habilidades necesarias para el emprendimiento social en cada asignatura.

\section{Metodología}

Esta investigación utiliza la metodologia colaborativa (Gallagher y Wessels, 2011) para responder a los objetivos propuestos. Un grupo motor de 12 docentes de las Universidades de Granada, Málaga y Sevilla se implicó en un proyecto colaborativo. El grupo de docentes pertenecía a los ámbitos de la Educación y de la Economía, y aportaron al proyecto 31 asignaturas de Grado y Posgrado $\left(n_{1}=31\right)$. Las asignaturas implicaron a 52 grupos de docencia diferentes que suponen un alumnado neto de 1592 estudiantes. En el trabajo colaborativo participaron tres personas externas a la Universidad con experiencia en ámbitos de emprendimiento y economía social, y estudiantes de varias de las asignaturas implicadas en el proyecto. A partir de las reuniones periódicas grupales se inició un proceso de 
construcción de herramientas de recogida de información y reflexión que permitieran cumplir con los objetivos propuestos.

\subsection{Procedimiento}

Para esta investigación se diseñaron dos herramientas de recogida de datos. En primer lugar, un registro para el profesorado que se denominó RESAU (Registro de Emprendimiento Social en las Aulas Universitarias). El registro fue construido a partir de varias fuentes bibliográficas sobre competencias de emprendimiento y economía social (Capella, Gil, Martí y Ruiz-Bernardo, 2016; García-Lira, Cantón, y Torreblanca, 2015; Sáenz y López, 2015; entre otras). Por lo tanto, el instrumento conjugaba competencias específicas de emprendimiento, componentes prosociales y elementos transversales relacionados con el emprendimiento social. La versión inicial fue validada por 14 jueces expertos en metodología de investigación y emprendimiento social. La versión para el profesorado definitiva (RESAU v1) se estructuró en cuatro dimensiones principales: a) valores (implicación, compromiso con diferentes realidades sociales, empatía, sentido ético,...); b) cualidades interpersonales (iniciativa y proactividad, autoconfianza, actitud positiva, flexibilidad, constancia y dedicación, responsabilidad, control de situaciones,...); c) capacidades (liderazgo, relación efectiva con otros, trabajo en equipo, comunicación, escucha empática y asertiva, automotivación,...); y d) apelación a la acción (respuestas innovadoras, generación de ideas, idear y construir iniciativas, organizar,...). El instrumento RESAU v1 para el profesorado pretendía identificar el grado en que las competencias de emprendimiento social se trabajaban en las asignaturas universitarias y, por tanto, realizar un diagnóstico. Además, este instrumento pretendía ser un recurso para la reflexión, reservando un espacio para registrar las posibilidades de mejorar cada una de las competencias que se habían valorado inicialmente. Tras seleccionar cinco de ellas, el propio instrumento solicitaba al docente que realizara un similar número de propuestas de mejora que tuviese la posibilidad de llevar a cabo en su asignatura para el próximo curso. De esta manera, el RESAU v1 se configuró como un recurso de diagnóstico, reflexión y orientado a la elaboración de propuestas y acciones de mejora.

En segundo lugar, el RESAU v1 fue adaptado para su aplicación a los estudiantes. Esta segunda versión del instrumento debería permitir confirmar en qué medida las competencias de emprendimiento social se estaban trabajando de manera efectiva en las clases de las asignaturas implicadas. Como escala de valoración, el RESAU v2, versión para el alumnado, constó de las mismas dimensiones que la versión para el profesorado. Esta nueva versión fue validada también por los mismos 14 expertos y sobre ella se realizó un estudio de fiabilidad (consistencia interna) y validez (análisis factorial de componentes principales). La validación estadística se realizó sobre la aplicación del instrumento en el primer trimestre de 2018. La muestra de estudiantes $\left(n_{2}=180\right)$, que pertenecía a las tres universidades participantes, estaba conformada por 63 hombres (35\%) y 116 mujeres $(64,4 \%)$, con una edad media de 22,26 años ( $D S=5,06)$. Tanto en este, como en el caso de la aplicación del RESAU v1 $\left(n_{1}=31\right)$, el muestreo fue incidental, tratando que los elementos de la muestra representaran adecuadamente 
la diversidad de universidades y asignaturas implicadas en la investigación, tanto por parte del alumnado como del profesorado.

El análisis de la consistencia interna a través del coeficiente alpha de Cronbach arrojó un resultado de 0,98 . El análisis factorial de componentes principales validó la estructura original, confirmando un modelo factorial con los mismos cuatro componentes (dimensiones) que explicaban el $74,96 \%$ de la variabilidad total. Las cuatro dimensiones arrojaron valores altos o aceptables de alpha de Cronbach: a) 0,97 ; b) 0,85 ; c) 0,68 ; y d) 0,62 . Para el análisis factorial se habían comprobado previamente las condiciones de aplicación $(\mathrm{KMO}=0,96$; Prueba de esfericidad de Barlett: $\chi^{2}=6597,85$, con 561 gl. y $p \leq 0,0005$ ).

Sobre los datos recabados del profesorado (RESAU v1) se realizó un estudio descriptivo. El carácter cuasi-cuantitativo de los datos y el tamaño de la muestra no ha permitido realizar otros análisis más profundos. En este sentido, se advierte sobre la necesidad de aumentar el tamaño de la muestra del profesorado y los estudiantes, así como el número de asignaturas y titulaciones oficiales universitarias a analizar para obtener resultados más concluyentes. No obstante, como se verá en el siguiente apartado, el análisis descriptivo realizado ha sido muy útil para identificar las competencias trabajadas, o no, en las asignaturas y los márgenes y propuestas de mejora, proporcionando unos resultados muy valiosos para la reflexión del propio profesorado. Con los datos de los estudiantes (procedentes del RESAU v2) se han realizado estudios descriptivos (medias y desviación estándar, frecuencias y porcentajes) e inferenciales bivariantes y multivariantes (análisis de varianza y análisis multivariante de la varianza), que han permitido relacionar las variables género, rama de conocimiento y universidad de procedencia. Todos los análisis han sido realizados con el paquete estadístico SPSS v.23.

\section{Resultados}

La aplicación de las dos versiones del instrumento ha producido resultados complementarios. En primer lugar, se exponen los resultados de los análisis realizados a los datos obtenidos con el RESAU v1 (profesorado) sobre las valoraciones de las competencias de emprendimiento social desarrolladas en las asignaturas universitarias, su posible margen de mejora y las propuestas de acción dirigidas al siguiente curso. En segundo lugar, se exponen los resultados del análisis efectuado a los datos del RESAU v2, aplicado a una muestra de estudiantes $\left(n_{2}=180\right)$. Como se verá en los resultados que se presentan a continuación, aunque la profundización en los análisis es muy diferente, siguen una tendencia similar, sobre todo en la valoración de las competencias para el emprendimiento social.

\subsection{Resultados del profesorado}

En las tablas siguientes se presentan los resultados de la aplicación del registro de profesorado sobre sus asignaturas (RESAU v1). En primer lugar, se presenta una tabla con las competencias de emprendimiento social que los docentes piensan que trabajan más en sus asignaturas (Tabla 1). Después se señalan las competencias que 
menos son desarrolladas en sus clases, en función de la opinión del profesorado (Tabla 2). También, se destacan las competencias que los docentes indican que pueden tener un margen de mejora dentro del currículum de sus materias (Tabla 3). Finalmente, se incluye una tabla con algunos ejemplos de las propuestas concretas de mejora para incluir competencias de emprendimiento social en sus asignaturas en el próximo curso (Tabla 4).

Entre las competencias más trabajadas se encuentran una mayor representación de los valores (a) y de las cualidades interpersonales (b), y una menor de las capacidades (c) y de la apelación a la acción (d). El "sentido ético" (a) y el "trato igualitario" (c) se encuentran en los primeros lugares con una mediana de 3,50. También, se observan en los primeros lugares el "pensamiento crítico" (a), la "implicación y el compromiso con diferentes realidades sociales" (a), la "responsabilidad" (b) y la "inclusividad y atención a la diversidad" (d), estas últimas con valores de mediana entre 3 y 3,25. Otras competencias que han sido reunidas bajo la dimensión de cualidades interpersonales bien valoradas son la "autoconfianza y actitud positiva" $(2,75)$, la "autonomía", la "flexibilidad para adoptar e implicarse en los cambios" y la "capacidad de percibir que el éxito depende del esfuerzo propio, con independencia de las circunstancias externas" (todas ellas valoradas con un 2,50).

Tabla. 1. Competencias de emprendimiento social más trabajadas en las asignaturas según los docentes.

\begin{tabular}{|l|c|}
\hline \multicolumn{1}{|c|}{ Competencias } & Valoración* \\
\hline a.1. Implicación y compromiso con diferentes realidades sociales & 3,00 \\
\hline a.3. Pensamiento crítico & 3,25 \\
\hline a.4. Perspectiva de género & 2,50 \\
\hline $\begin{array}{l}\text { a.5. Sentido ético (principios y normas basadas en el respeto a las } \\
\text { personas y a nuestro entorno) }\end{array}$ & 3,50 \\
\hline $\begin{array}{l}\text { b.2. Autonomía (capacidad de búsqueda de independencia y } \\
\text { libertad de acción) }\end{array}$ & 2,50 \\
\hline b.3. Flexibilidad para adoptar e implicarse en los cambios & 2,50 \\
\hline \begin{tabular}{l} 
b.6. Autoconfianza y actitud positiva \\
\hline $\begin{array}{l}\text { b.7. Responsabilidad (capacidad de ser consciente de sus } \\
\text { obligaciones y actuar conforme a ellas, reconociendo las } \\
\text { consecuencias de sus decisiones) }\end{array}$
\end{tabular} & 3,00 \\
\hline $\begin{array}{l}\text { b.8. Capacidad de percibir que el éxito depende del esfuerzo } \\
\text { propio, con independencia de las circunstancias externas }\end{array}$ & 2,50 \\
\hline $\begin{array}{l}\text { c.7. Automotivarse y motivar a otras personas con las que se } \\
\text { trabaja }\end{array}$ & 2,50 \\
\hline c.10. Trato igualitario & 3,50 \\
\hline d.8. Inclusividad y atención a la diversidad & 3,00 \\
\hline
\end{tabular}

* Los valores de esta columna se han expresado en medianas. La escala empleada era de 0 a 4. 
En la siguiente tabla se presentan las competencias menos desarrolladas en las materias universitarias en opinión del profesorado. Como aspecto positivo se puede señalar que no aparece ningún ítem relativo a valores (a), y solo uno relacionado con capacidades (c). La mayoría se corresponden con competencias de cualidades interpersonales (b) y de apelación a la acción (d). Estas últimas, precisamente, son las que menos se trabajan: "que se generen ideas e identifiquen oportunidades emprendedoras" e "iniciar, construir y hacer realidad iniciativas", con una mediana de 1,25. Ambas de la dimensión apelación a la acción (d). Esta misma dimensión, se puede recordar, era la que menos representación tenía en las competencias más valoradas (ver Tabla 1). Otras competencias menos valoradas pertenecen a la dimensión cualidades interpersonales (b), con una mediana de 1,75, que son la "capacidad de superar adversidades y sobreponerse al fracaso", la de "planificar para responder en situaciones difíciles con incertidumbre", y la "capacidad de aceptar riesgos y asumir las responsabilidades que pueden suponer", todas ellas con una mediana de 1,75 . De las capacidades (c) la única representante entre las menos valorada es la capacidad de "seleccionar a las personas que van a formar parte de su grupo de trabajo de manera no arbitraria" con una mediana de 1,50.

Tabla. 2. Competencias de emprendimiento social menos desarrolladas en las asignaturas según los docentes.

\begin{tabular}{|l|c|}
\hline \multicolumn{1}{|c|}{ Competencias } & Valoración* \\
\hline b.5. Capacidad de superar adversidades y sobreponerse al fracaso & 1,75 \\
\hline $\begin{array}{l}\text { b.10. Planificar para responder en situaciones difíciles con } \\
\text { incertidumbre }\end{array}$ & 1,75 \\
\hline $\begin{array}{l}\text { b.11. Capacidad de aceptar riesgos y asumir las responsabilidades } \\
\text { que pueden suponer }\end{array}$ & 1,75 \\
\hline $\begin{array}{l}\text { c.8. Seleccionar a las personas que van a formar parte de su grupo } \\
\text { de trabajo de manera no arbitraria }\end{array}$ & 1,50 \\
\hline $\begin{array}{l}\text { d.2. Que se generen ideas e identifiquen oportunidades } \\
\text { emprendedoras }\end{array}$ & 1,25 \\
\hline d.3. Iniciar, construir y hacer realidad iniciativas & 1,25 \\
\hline
\end{tabular}

* Los valores de esta columna se han expresado en medianas. La escala empleada era de 0 a 4.

Todas las competencias tienen margen de mejora. No obstante, en opinión del profesorado y dependiendo de la asignatura de la que se trate, unas competencias tienen algún grado mayor de mejora que otras. En la Tabla 3 se reúnen las competencias que se han señalado con más margen de mejora. Algunas veces coinciden con aquellas que eran poco valoradas. Otras veces se señalan competencias que ya tenían una valoración media y que, en la opinión del profesorado, podrían mejorarse aún más. Como se observa en la Tabla 3, no hay ninguna competencia incluida, entre las que se sitúan con mayor margen de mejora, de los valores (a), pero sí existen de cualidades interpersonales (b), y de apelación 
a la acción (d). Estas dos últimas dimensiones eran las que menos habían sido consideradas a la hora de trabajar en clase. Así, se observa como la b.5 coincide en las Tablas 2 y 3: "Capacidad de superar adversidades y sobreponerse al fracaso". También hay otra coincidencia entre ambas tablas en la dimensión de capacidades (c). Se trata de la relativa a "seleccionar a las personas que van a formar parte de su grupo de trabajo de manera no arbitraria". Otra cuestión a destacar en la Tabla 3 es la aparición en la misma de una competencia de las más trabajadas. Se trata de la "Flexibilidad para adoptar e implicarse en los cambios", perteneciente a la dimensión de cualidades interpersonales (b) que ya había sido incluida como de las más trabajadas (valoración de 2,50), y que ahora se indica que tiene un margen de mejora de 2,25 .

Tabla. 3. Competencias de emprendimiento social con más margen de mejora según los docentes.

\begin{tabular}{|l|c|}
\hline \multicolumn{1}{|c|}{ Competencias } & Valoración* \\
\hline b.3. Flexibilidad para adoptar e implicarse en los cambios & 2,25 \\
\hline b.5. Capacidad de superar adversidades y sobreponerse al fracaso & 2,75 \\
\hline $\begin{array}{l}\text { b.7. Capacidad de percibir que el éxito depende del esfuerzo } \\
\text { propio, con independencia de las circunstancias externas }\end{array}$ & 2,25 \\
\hline $\begin{array}{l}\text { c.2. Relacionarse de manera efectiva con otros grupos, colectivos } \\
\text { y/o entidades externas a la clase }\end{array}$ & 2,25 \\
\hline $\begin{array}{l}\text { c.3. Trabajo en equipo } \\
\text { c.4. Comunicarse eficazmente con diferentes personas y en } \\
\text { diversas situaciones }\end{array}$ & 2,75 \\
\hline $\begin{array}{l}\text { c.7. Automotivarse y motivar a otras personas con las que se } \\
\text { trabaja }\end{array}$ & 2,25 \\
\hline $\begin{array}{l}\text { c.8. Seleccionar a las personas que van a formar parte de su grupo } \\
\text { de trabajo de manera no arbitraria }\end{array}$ & 2,50 \\
\hline c.9. Repartir y coordinar tareas y funciones de manera competente & 2,50 \\
\hline $\begin{array}{l}\text { d.2. Que se generen ideas e identifiquen oportunidades } \\
\text { emprendedoras }\end{array}$ & 2,50 \\
\hline $\begin{array}{l}\text { d.5. Seleccionar la mejor alternativa para actuar, de forma } \\
\text { consecuente y comprometida }\end{array}$ & 2,25 \\
\hline $\begin{array}{l}\text { d.6. Capacidad de organizar de manera ordenada, coherente y } \\
\text { pragmática }\end{array}$ & 2,25 \\
\hline
\end{tabular}

*Los valores de esta columna se han expresado en medianas. La escala empleada era de 0 a 4.

\subsection{Resultados de los estudiantes}

En este apartado se consideran los datos recogidos con la muestra de estudiantes $\left(n_{2}=180\right)$ tras la aplicación del RESAU v2. La estrategia de análisis siguió un 
proceso paso a paso, de complejidad progresiva, añadiendo o eliminando variables en el análisis, teniendo en cuenta los resultados que se iban obteniendo. Así, de las primeras pruebas $\mathrm{T}$ de muestras independientes considerando las variables género $\mathrm{y}$ rama de conocimiento, se pasó a un análisis de varianza, que incorporó a la variable Universidad de procedencia, hasta la realización de un análisis multivariante de la varianza (MANOVA).

Las pruebas $\mathrm{T}$ realizadas sobre la variable rama de conocimiento (Educación o Económicas) ofreció resultados significativos en todas las competencias. En todos los casos las medias obtenidas por los estudiantes de Educación fueron superiores a las obtenidas por los estudiantes de Económicas. En la Tabla 5 se recoge un resumen de los análisis realizados. Como se realizaron en cada caso la prueba de Levene sobre la calidad de las varianzas, cuando no se pudo asumir que las varianzas de cada grupo fueran iguales se realizó la corrección correspondiente de los grados de libertad y de la prueba $\mathrm{T}$ (en la Tabla 5 se han señalado la $\mathrm{T}$ corregida con un $*$ ).

Tabla. 5. Pruebas T para muestras independientes por Rama de Conocimiento.

\begin{tabular}{|l|c|c|c|c|}
\hline \multicolumn{1}{|c|}{ Competencias } & $T$ & g.l & $p$ & $\begin{array}{l}\text { Dif. de } \\
\text { medias }\end{array}$ \\
\hline $\begin{array}{l}\text { a.1. Implicación y el compromiso con } \\
\text { diferentes realidades sociales }\end{array}$ & $6,46^{*}$ & 176,93 & 0,000 & 0,91 \\
\hline $\begin{array}{l}\text { a.2. Conciencia del otro (capacidad de } \\
\text { comprender y actuar en función de las } \\
\text { problemáticas y necesidades personales, } \\
\text { profesionales y sociales de otras personas) }\end{array}$ & 7,39 & 178 & 0,000 & 1,15 \\
\hline $\begin{array}{l}\text { a.3. Pensamiento crítico } \\
\text { a.4. Perspectiva de género }\end{array}$ & $6,29^{*}$ & 177,84 & 0,000 & 0,93 \\
\hline $\begin{array}{l}\text { a.5. Sentido ético (principios y normas } \\
\text { basadas en el respeto a las personas y a } \\
\text { nuestro entorno) }\end{array}$ & $9,55^{*}$ & 170,53 & 0,000 & 1,34 \\
\hline $\begin{array}{l}\text { b.1. Iniciativa y proactividad (capacidad de } \\
\text { promover iniciativas; introducir nuevos } \\
\text { productos, servicios o tecnología } \\
\text { innovadora; ynticiparse a los problemas } \\
\text { futuros, necesidades o cambios) }\end{array}$ & 5,04 & 177,95 & 0,000 & 0,74 \\
\hline $\begin{array}{l}\text { b.2. Autonomía (capacidad de búsqueda de } \\
\text { independencia y libertad de acción) }\end{array}$ & $4,96^{*}$ & 178,00 & 0,000 & 0,7 \\
\hline $\begin{array}{l}\text { b.3. Flexibilidad para adoptar e implicarse } \\
\text { en los cambios }\end{array}$ & $7,15^{*}$ & 177,83 & 0,000 & 1 \\
\hline $\begin{array}{l}\text { b.4. Constancia, dedicación y determinación } \\
\text { en tareas de inicio a fin }\end{array}$ & $2,69^{*}$ & 177,81 & 0,010 & 0,37 \\
\hline
\end{tabular}




\begin{tabular}{|c|c|c|c|c|}
\hline $\begin{array}{l}\text { b.5. Capacidad de superar adversidades y } \\
\text { sobreponerse al fracaso }\end{array}$ & $3,68^{*}$ & 175,12 & 0,000 & 0,54 \\
\hline b.6. Autoconfianza y actitud positiva & $5,26^{*}$ & 177,69 & 0,000 & 0,78 \\
\hline $\begin{array}{l}\text { b.7. Responsabilidad (capacidad de ser } \\
\text { consciente de sus obligaciones y actuar } \\
\text { conforme a ellas, reconociendo las } \\
\text { consecuencias de sus decisiones) }\end{array}$ & $3,45^{*}$ & 177,23 & 0,000 & 0,43 \\
\hline $\begin{array}{l}\text { b.8. Capacidad de percibir que el éxito } \\
\text { depende del esfuerzo propio, con } \\
\text { independencia de las circunstancias externas }\end{array}$ & $2,43 *$ & 178,00 & 0,020 & 0,35 \\
\hline $\begin{array}{l}\text { b.9. Capacidad de control en situaciones } \\
\text { difíciles y bajo presión }\end{array}$ & $2,95^{*}$ & 178,00 & 0,000 & 0,47 \\
\hline $\begin{array}{l}\text { b.10. Planificar para responder } \\
\text { situaciones difíciles con incertidumbre }\end{array}$ & $2,51 *$ & 178,00 & 0,010 & 0,38 \\
\hline $\begin{array}{l}\text { b.11. Capacidad de aceptar riesgos y asumir } \\
\text { las responsabilidades que pueden suponer }\end{array}$ & $4,63 *$ & 176,12 & 0,000 & 0,67 \\
\hline c.1. Liderazgo & $6,43 *$ & 178,00 & 0,000 & 1,12 \\
\hline $\begin{array}{l}\text { c.2. Relacionarse de manera efectiva con } \\
\text { otros grupos, colectivos y/o entidades } \\
\text { externas a la clase }\end{array}$ & $9,63 *$ & 176,96 & 0,000 & 1,71 \\
\hline c.3. Trabajo en equipo & $12,37^{*}$ & 172,85 & 0,000 & 2,00 \\
\hline $\begin{array}{l}\text { c.4. Comunicarse eficazmente con diferentes } \\
\text { personas y en diversas situaciones }\end{array}$ & $8,12^{*}$ & 175,95 & 0,000 & 1,58 \\
\hline c.5. Escucha empática y asertiva & $8,74 *$ & 175,92 & 0,000 & 1,28 \\
\hline $\begin{array}{l}\text { c.6. Interpretar emociones y dar feedback a } \\
\text { otras personas }\end{array}$ & $7,87^{*}$ & 177,99 & 0,000 & 1,47 \\
\hline $\begin{array}{l}\text { c.7. Automotivarse y motivar a otras } \\
\text { personas con las que se trabaja }\end{array}$ & $9,74 *$ & 177,80 & 0,000 & 1,29 \\
\hline $\begin{array}{l}\text { c.8. Seleccionar a las personas que van a } \\
\text { formar parte de su grupo de trabajo de } \\
\text { manera no arbitraria }\end{array}$ & $11,29^{*}$ & 176,87 & 0,000 & 1,62 \\
\hline $\begin{array}{l}\text { c.9. Repartir y coordinar tareas y funciones } \\
\text { de manera competente }\end{array}$ & $7,28 *$ & 169,56 & 0,000 & 1,78 \\
\hline c.10.Trato igualitario & $7,53 *$ & 172,44 & 0,000 & 1,12 \\
\hline $\begin{array}{l}\text { d.1. Que se den respuestas innovadoras y } \\
\text { creativas a problemas planteados }\end{array}$ & $6,67 *$ & 175,64 & 0,000 & 1,16 \\
\hline $\begin{array}{l}\text { d.2. Que se generen ideas e identifiquen } \\
\text { oportunidades emprendedoras }\end{array}$ & $8,22 *$ & 177,60 & 0,000 & 1,04 \\
\hline $\begin{array}{l}\text { d.3. Iniciar, construir y hacer realidad } \\
\text { iniciativas }\end{array}$ & $5,97 *$ & 177,89 & 0,000 & 1,27 \\
\hline
\end{tabular}




\begin{tabular}{|l|c|c|c|c|}
\hline $\begin{array}{l}\text { d.4. Establecer metas claras, no simples, } \\
\text { pero alcanzables }\end{array}$ & $6,32^{*}$ & 174,62 & 0,000 & 0,88 \\
\hline $\begin{array}{l}\text { d.5. Seleccionar la mejor alternativa para } \\
\text { actuar, de forma consecuente y } \\
\text { comprometida }\end{array}$ & $5,91^{*}$ & 177,50 & 0,000 & 0,89 \\
\hline $\begin{array}{l}\text { d.6. Capacidad de organizar de manera } \\
\text { ordenada, coherente y pragmática }\end{array}$ & $8,46^{*}$ & 177,15 & 0,000 & 0,88 \\
\hline $\begin{array}{l}\text { d.7. Perspectiva de género en los grupos de } \\
\text { trabajo }\end{array}$ & $7,77^{*}$ & 177,98 & 0,000 & 1,33 \\
\hline
\end{tabular}

Como se observa en la Tabla 5, todas las comparaciones de medias son significativas. En todos los casos las medias siempre son mayores en la percepción que tienen los estudiantes de la rama de Educación, con respecto a los de Económicas, sobre que en sus clases se trabajan más las competencias de emprendimiento social. Los casos más llamativos se producen en la competencia c.3. "Trabajo en equipo", donde la diferencia llega a ser de dos puntos.

En la Tabla 6 se muestran las medias de una y otra rama de conocimiento.

Tabla. 6. Medias por Rama de Conocimiento.

\begin{tabular}{|l|c|c|}
\hline \multicolumn{1}{|c|}{ Competencias } & Educación & Económicas \\
\hline $\begin{array}{l}\text { a.1. Implicación y el compromiso con diferentes } \\
\text { realidades sociales }\end{array}$ & 3,17 & 2,26 \\
\hline $\begin{array}{l}\text { a.2. Conciencia del otro (capacidad de comprender } \\
\text { y actuar en función de las problemáticas y } \\
\text { necesidades personales, profesionales y sociales de } \\
\text { otras personas) }\end{array}$ & 3,23 & 2,08 \\
\hline a.3. Pensamiento crítico & 3,24 & 2,31 \\
\hline a.4. Perspectiva de género & 3,09 & 2,03 \\
\hline $\begin{array}{l}\text { a.5. Sentido ético (principios y normas basadas en } \\
\text { el respeto a las personas y a nuestro entorno) }\end{array}$ & 3,31 & 1,97 \\
\hline $\begin{array}{l}\text { b.1. Iniciativa y proactividad (capacidad de } \\
\text { promover iniciativas; introducir nuevos productos, } \\
\text { servicios o tecnología innovadora; y anticiparse a } \\
\text { los problemas futuros, necesidades o cambios) }\end{array}$ & 2,96 & 2,22 \\
\hline $\begin{array}{l}\text { b.2. Autonomía (capacidad de búsqueda de } \\
\text { independencia y libertad de acción) }\end{array}$ & 3,12 & 2,42 \\
\hline $\begin{array}{l}\text { b.3. Flexibilidad para adoptar e implicarse en los } \\
\text { cambios }\end{array}$ & 3,29 & 2,29 \\
\hline $\begin{array}{l}\text { b.4.Constancia, dedicación y determinación en } \\
\text { tareas de inicio a fin }\end{array}$ & 3,23 & 2,86 \\
\hline $\begin{array}{l}\text { b.5. Capacidad de superar adversidades y } \\
\text { sobreponerse al fracaso }\end{array}$ & 2,99 & 2,45 \\
\hline \begin{tabular}{l} 
b.6. Autoconfianza y actitud positiva \\
\hline
\end{tabular} & 3,16 & 2,38 \\
\hline
\end{tabular}




\begin{tabular}{|c|c|c|}
\hline $\begin{array}{l}\text { b.7. Responsabilidad (capacidad de ser consciente } \\
\text { de sus obligaciones y actuar conforme a ellas, } \\
\text { reconociendo las consecuencias de sus decisiones) }\end{array}$ & 3,11 & 2,68 \\
\hline $\begin{array}{l}\text { b.8. Capacidad de percibir que el éxito depende del } \\
\text { esfuerzo propio, con independencia de las } \\
\text { circunstancias externas }\end{array}$ & 3,16 & 2,81 \\
\hline $\begin{array}{l}\text { b.9. Capacidad de control en situaciones difíciles y } \\
\text { bajo presión }\end{array}$ & 2,73 & 2,26 \\
\hline $\begin{array}{l}\text { b.10. Planificar para responder en situaciones } \\
\text { difíciles con incertidumbre }\end{array}$ & 2,81 & 2,43 \\
\hline $\begin{array}{l}\text { b.11. Capacidad de aceptar riesgos y asumir las } \\
\text { responsabilidades que pueden suponer }\end{array}$ & 2,96 & 2,29 \\
\hline c.1. Liderazgo & 2,53 & 1,41 \\
\hline $\begin{array}{l}\text { c.2. Relacionarse de manera efectiva con otros } \\
\text { grupos, colectivos y/o entidades externas a la clase }\end{array}$ & 3,03 & 1,32 \\
\hline c.3. Trabajo en equipo & 3,40 & 1,40 \\
\hline $\begin{array}{l}\text { c.4. Comunicarse eficazmente con diferentes } \\
\text { personas y en diversas situaciones }\end{array}$ & 3,15 & 1,57 \\
\hline c.5. Escucha empática y asertiva & 3,09 & 1,81 \\
\hline $\begin{array}{l}\text { c.6. Interpretar emociones y dar feedback a otras } \\
\text { personas }\end{array}$ & 2,95 & 1,48 \\
\hline $\begin{array}{l}\text { c.7. Automotivarse y motivar a otras personas con } \\
\text { las que se trabaja }\end{array}$ & 2,96 & 1,67 \\
\hline $\begin{array}{l}\text { c.8. Seleccionar a las personas que van a formar } \\
\text { parte de su grupo de trabajo de manera no arbitraria }\end{array}$ & 2,99 & 1,37 \\
\hline $\begin{array}{l}\text { c.9. Repartir y coordinar tareas y funciones de } \\
\text { manera competente }\end{array}$ & 3,20 & 1,42 \\
\hline c.10.Trato igualitario & 3,43 & 2,31 \\
\hline $\begin{array}{l}\text { d.1. Que se den respuestas innovadoras y creativas } \\
\text { a problemas planteados }\end{array}$ & 3,23 & 2,07 \\
\hline $\begin{array}{l}\text { d.2. Que se generen ideas e identifiquen } \\
\text { oportunidades emprendedoras }\end{array}$ & 2,91 & 1,87 \\
\hline d.3. Iniciar, construir y hacer realidad iniciativas & 3,09 & 1,82 \\
\hline $\begin{array}{l}\text { d.4. Establecer metas claras, no simples, pero } \\
\text { alcanzables }\end{array}$ & 3,03 & 2,15 \\
\hline $\begin{array}{l}\text { d.5. Seleccionar la mejor alternativa para actuar, de } \\
\text { forma consecuente y comprometida }\end{array}$ & 3,13 & 2,24 \\
\hline $\begin{array}{l}\text { d.6. Capacidad de organizar de manera ordenada, } \\
\text { coherente y pragmática }\end{array}$ & 3,19 & 2,31 \\
\hline d.7. Perspectiva de género en los grupos de trabajo & 3,17 & 1,84 \\
\hline d.8. Inclusividad y atención a la diversidad & 3,13 & 1,95 \\
\hline
\end{tabular}

Mientras que con las ramas de conocimiento se producen diferencias significativas en todas las competencias incluidas en el RESAU v2, cuando la prueba $\mathrm{T}$ se realiza con la variable género, casi no se encuentran diferencias. En la Tabla 7 se muestran las únicas dos diferencias significativas encontradas. Las 
mujeres consideran que en clase se promueve menos la "capacidad de percibir que el éxito depende del esfuerzo propio, con independencia de las circunstancias externas". Lo mismo ocurre con "la planificación para responder a situaciones difíciles con incertidumbre", ellas también piensan que se trabaja esa competencia en clase menos que ellos (ver Tabla 7).

Tabla. 7. Pruebas T significativas para muestras independientes por Género.

\begin{tabular}{|l|c|c|c|c|}
\hline Competencias & $T$ & g.l & $p$ & $\begin{array}{c}\text { Dif. de } \\
\text { medias }\end{array}$ \\
\hline $\begin{array}{l}\text { b.8. Capacidad de percibir que el éxito } \\
\text { depende del esfuerzo propio, con } \\
\text { independencia de las circunstancias } \\
\text { externas }\end{array}$ & 1,99 & 177 & 0,049 & 0,30 \\
\hline $\begin{array}{l}\text { b.10. Planificar para responder en } \\
\text { situaciones difíciles con incertidumbre }\end{array}$ & 2,02 & 149,91 & 0,045 & 0,30 \\
\hline
\end{tabular}

Para incorporar en el modelo de análisis la variable Universidad de procedencia, y al tener estas tres categorías (Universidades de Granada, Málaga y Sevilla), y poder considerar todas las competencias al mismo tiempo en un mismo análisis (varias variables dependientes), fue necesario emplear un análisis multivariante de la varianza (MANOVA). Al observar la poca influencia que la variable género podía tener en el modelo se decidió eliminarla. Para realizar los contrastes multivariados se obtuvieron la traza de Pillai, la Lambda de Wilks, la traza de Hotelling y la raíz mayor de Roy. Las pruebas $F$ que se realizaron contrastaron el efecto multivariante por Universidad de procedencia y por rama de conocimiento. En la siguiente tabla se muestran los contrastes para aceptar o rechazar las hipótesis nulas de independencia entre las competencias y las ramas de conocimiento y las universidades. Además se ha incluido el cálculo del tamaño del efecto a partir de coeficiente $\eta^{2}$ parcial (ver Tabla 8).

Tabla. 8. Pruebas T significativas para muestras independientes por Género.

\begin{tabular}{|c|l|l|l|c|c|c|}
\hline \multicolumn{1}{|c|}{ Efecto } & \multicolumn{1}{|c|}{ Contraste } & Valor & $F$ & $\begin{array}{c}\text { gl. } \\
\text { error }\end{array}$ & $p$ & $\eta^{2}$ \\
\hline \multirow{4}{*}{ Interceptación } & Traza de Pillai & 0,92 & 45,89 & 142 & 0,000 & 0,92 \\
\cline { 2 - 8 } & Lambda de Wilks & 0,08 & 45,89 & 142 & 0,000 & 0,92 \\
\cline { 2 - 8 } & $\begin{array}{l}\text { Traza de Hotelling y } \\
\text { Raíz mayor de Roy }\end{array}$ & 10,99 & 45,89 & 142 & 0,000 & 0,92 \\
\hline \multirow{2}{*}{\begin{tabular}{l} 
Ramas $\begin{array}{c}\text { Conocimiento } \\
\text { de }\end{array}$ \\
\cline { 2 - 8 }
\end{tabular}} & Traza de Pillai & 0,519 & 4,50 & 142 & 0,000 & 0,52 \\
\cline { 2 - 8 } & Lambda de Wilks & 0,481 & 4,50 & 142 & 0,000 & 0,52 \\
\hline
\end{tabular}




\begin{tabular}{|l|l|l|l|l|l|l|}
\hline & $\begin{array}{l}\text { Traza de Hotelling y } \\
\text { Raíz mayor de Roy }\end{array}$ & 1,08 & 4,50 & 142 & 0,000 & 0,52 \\
\hline \multirow{4}{*}{ Universidad } & Traza de Pillai & 0,43 & 1,15 & 286 & 0,22 & 0,21 \\
\cline { 2 - 8 } & Lambda de Wilks & 0,62 & 1,14 & 284 & 0,23 & 0,21 \\
\cline { 2 - 8 } & Traza de Hotelling & 0,55 & 1,13 & 282 & 0,24 & 0,21 \\
\cline { 2 - 7 } & Raíz mayor de Roy & 0,30 & 1,27 & 143 & 0,17 & 0,23 \\
\hline
\end{tabular}

En la tabla anterior (Tabla 8) se constata una vez más la importancia de las ramas de conocimiento en el modelo (valores de $p$ todos significativos y un tamaño del efecto $\left.\eta^{2}=0,52\right)$. La Universidad de pertenencia no parece tener mucha influencia. Sin embargo, cuando se observa la interceptación del modelo, el tamaño del efecto sube hasta 0,92. En las pruebas de efectos intersujetos realizadas se vuelve a constatar la relevancia en el modelo de las ramas de conocimiento (casi todos los contrastes son significativos), y la poca relevancia de la Universidad (algunos contrastes son significativos, pero los tamaños del efecto son pequeños). En la Tabla 9 se incluyen las pruebas de efectos intersujetos significativas incluyendo en cada caso el tamaño del efecto. A pesar de que se muestran todos los contrastes significativos $(p<0,005)$, los tamaños del efecto son pequeños. Destaca por encima del resto la competencia "c3. Trabajo en equipo" con un tamaño del efecto algo mayor $\left(\eta^{2}=0,31\right)$.

Tabla. 9. Pruebas de efectos intersujetos para Rama de Conocimiento y Universidad (solo significativas).

\begin{tabular}{|c|c|c|c|c|}
\hline & Competencias & $F$ & $p$ & $\eta^{2}$ \\
\hline \multirow{6}{*}{$\begin{array}{l}\text { Rama de } \\
\text { conocimiento }\end{array}$} & $\begin{array}{l}\text { a.1. Implicación y el compromiso con } \\
\text { diferentes realidades sociales }\end{array}$ & 14,92 & 0,000 & 0,08 \\
\hline & $\begin{array}{l}\text { a.2. Conciencia del otro (capacidad de } \\
\text { comprender y actuar en función de las } \\
\text { problemáticas y necesidades personales, } \\
\text { profesionales y sociales de otras } \\
\text { personas) }\end{array}$ & 30,22 & 0,000 & 0,15 \\
\hline & a.3. Pensamiento crítico & 12,20 & 0,001 & 0,07 \\
\hline & a.4. Perspectiva de género & 19,20 & 0,000 & 0,09 \\
\hline & $\begin{array}{l}\text { a.5. Sentido ético (principios y normas } \\
\text { basadas en el respeto a las personas y a } \\
\text { nuestro entorno) }\end{array}$ & 35,32 & 0,000 & 0,16 \\
\hline & $\begin{array}{l}\text { b.1. Iniciativa y proactividad (capacidad } \\
\text { de promover iniciativas; introducir }\end{array}$ & 8,58 & 0,004 & 0,05 \\
\hline
\end{tabular}




\begin{tabular}{|c|c|c|c|}
\hline $\begin{array}{l}\text { nuevos productos, servicios o tecnología } \\
\text { innovadora; y anticiparse a los problemas } \\
\text { futuros, necesidades o cambios) }\end{array}$ & & & \\
\hline $\begin{array}{l}\text { b.2. Autonomía (capacidad de búsqueda } \\
\text { de independencia y libertad de acción) }\end{array}$ & 9,19 & 0,003 & 0,05 \\
\hline $\begin{array}{l}\text { b.3. Flexibilidad para adoptar e implicarse } \\
\text { en los cambios }\end{array}$ & 27,67 & 0,000 & 0,14 \\
\hline $\begin{array}{ll}\text { b.4.Constancia, dedicación } & y \\
\text { determinación en tareas de inicio a fin } & \end{array}$ & 0,99 & 0,320 & 0,01 \\
\hline $\begin{array}{l}\text { b.5. Capacidad de superar adversidades y } \\
\text { sobreponerse al fracaso }\end{array}$ & 3,71 & 0,056 & 0,02 \\
\hline b.6. Autoconfianza y actitud positiva & 12,02 & 0,001 & 0,06 \\
\hline $\begin{array}{l}\text { b.7. Responsabilidad (capacidad de ser } \\
\text { consciente de sus obligaciones y actuar } \\
\text { conforme a ellas, reconociendo las } \\
\text { consecuencias de sus decisiones) }\end{array}$ & 2,85 & 0,093 & 0,02 \\
\hline $\begin{array}{l}\text { b.8. Capacidad de percibir que el éxito } \\
\text { depende del esfuerzo propio, con } \\
\text { independencia de las circunstancias } \\
\text { externas }\end{array}$ & 0,68 & 0,410 & 0,01 \\
\hline $\begin{array}{l}\text { b.9. Capacidad de control en situaciones } \\
\text { difíciles y bajo presión }\end{array}$ & 1,20 & 0,273 & 0,01 \\
\hline $\begin{array}{l}\text { b.10. Planificar para responder en } \\
\text { situaciones difíciles con incertidumbre }\end{array}$ & 0,90 & 0,343 & 0,01 \\
\hline $\begin{array}{l}\text { b.11. Capacidad de aceptar riesgos y } \\
\text { asumir las responsabilidades que pueden } \\
\text { suponer }\end{array}$ & 5,65 & 0,019 & 0,03 \\
\hline c.1. Liderazgo & 13,88 & 0,000 & 0,07 \\
\hline $\begin{array}{l}\text { c.2. Relacionarse de manera efectiva con } \\
\text { otros grupos, colectivos y/o entidades } \\
\text { externas a la clase }\end{array}$ & 51,56 & 0,000 & 0,23 \\
\hline c.3. Trabajo en equipo & 78,30 & 0,000 & 0,31 \\
\hline $\begin{array}{l}\text { c.4. Comunicarse eficazmente con } \\
\text { diferentes personas } y \text { en diversas } \\
\text { situaciones }\end{array}$ & 40,59 & 0,000 & 0,19 \\
\hline c.5. Escucha empática y asertiva & 23,84 & 0,000 & 0,12 \\
\hline $\begin{array}{l}\text { c.6. Interpretar emociones y dar feedback } \\
\text { a otras personas }\end{array}$ & 35,75 & 0,000 & 0,17 \\
\hline $\begin{array}{l}\text { c.7. Automotivarse y motivar a otras } \\
\text { personas con las que se trabaja }\end{array}$ & 23,45 & 0,000 & 0,12 \\
\hline $\begin{array}{l}\text { c.8. Seleccionar a las personas que van a } \\
\text { formar parte de su grupo de trabajo de } \\
\text { manera no arbitraria }\end{array}$ & 50,63 & 0,000 & 0,22 \\
\hline
\end{tabular}




\begin{tabular}{|c|c|c|c|c|}
\hline & $\begin{array}{l}\text { c.9. Repartir y coordinar tareas y } \\
\text { funciones de manera competente }\end{array}$ & 61,80 & 0,000 & 0,26 \\
\hline & c.10. Trato igualitario & 18,14 & 0,000 & 0,09 \\
\hline & $\begin{array}{l}\text { d.1. Que se den respuestas innovadoras y } \\
\text { creativas a problemas planteados }\end{array}$ & 20,70 & 0,000 & 0,11 \\
\hline & $\begin{array}{l}\text { d.2. Que se generen ideas e identifiquen } \\
\text { oportunidades emprendedoras }\end{array}$ & 11,34 & 0,000 & 0,06 \\
\hline & $\begin{array}{l}\text { d.3. Iniciar, construir y hacer realidad } \\
\text { iniciativas }\end{array}$ & 25,56 & 0,000 & 0,13 \\
\hline & $\begin{array}{l}\text { d.4. Establecer metas claras, no simples, } \\
\text { pero alcanzables }\end{array}$ & 11,59 & 0,001 & 0,06 \\
\hline & $\begin{array}{l}\text { d.5. Seleccionar la mejor alternativa para } \\
\text { actuar, de forma consecuente y } \\
\text { comprometida }\end{array}$ & 15,39 & 0,000 & 0,08 \\
\hline & $\begin{array}{l}\text { d.6. Capacidad de organizar de manera } \\
\text { ordenada, coherente y pragmática }\end{array}$ & 11,31 & 0,001 & 0,06 \\
\hline & $\begin{array}{l}\text { d.7. Perspectiva de género en los grupos } \\
\text { de trabajo }\end{array}$ & 24,19 & 0,000 & 0,12 \\
\hline & a.4. Perspectiva de género & 4,16 & 0,018 & 0,05 \\
\hline & $\begin{array}{l}\text { b.8. Capacidad de percibir que el éxito } \\
\text { depende del esfuerzo propio, con } \\
\text { independencia de las circunstancias } \\
\text { externas }\end{array}$ & 4,60 & 0,011 & 0,05 \\
\hline & $\begin{array}{l}\text { b.9. Capacidad de control en situaciones } \\
\text { difíciles y bajo presión }\end{array}$ & 4,65 & 0,011 & 0,05 \\
\hline Universidad & $\begin{array}{l}\text { b.10. Planificar para responder en } \\
\text { situaciones difíciles con incertidumbre }\end{array}$ & 3,57 & 0,030 & 0,04 \\
\hline & c.1. Liderazgo & 3,42 & 0,035 & 0,04 \\
\hline & $\begin{array}{l}\text { c.7. Automotivarse y motivar a otras } \\
\text { personas con las que se trabaja }\end{array}$ & 3,30 & 0,039 & 0,04 \\
\hline & $\begin{array}{l}\text { d.2. Que se generen ideas e identifiquen } \\
\text { oportunidades emprendedoras }\end{array}$ & 5,43 & 0,010 & 0,05 \\
\hline & $\begin{array}{llll}\text { d.8. Inclusividad } \\
\text { diversidad }\end{array}$ & 3,26 & 0,031 & 0,04 \\
\hline
\end{tabular}

\section{Conclusiones}

Las conclusiones del trabajo destacan la relevancia de trabajar las competencias para el emprendimiento social en las aulas universitarias y ponen de relieve la manera en que cada docente plantea estrategias de mejora. De este modo, el empleo de esta herramienta contribuye a que el docente adopte un enfoque innovador, adecuando su enseñanza a la formación de competencias profesionales 
que permita a los estudiantes adquirir recursos (destrezas, habilidades, actitudes, ...) para emprender con un fuerte componente ético y valor social.

García-Lira et al. (2015), señalan que una de las formas para motivar la actitud emprendedora del alumnado es utilizar una encuesta para conocer sus opiniones, concepciones y percepciones sobre las finalidades y funciones de un emprendedor, así como sus competencias para detectar oportunidades emprendedoras y extraer resultados con valor social. También, Capella et al. (2016), indican que los cuestionarios son un instrumento válido para identificar los rasgos característicos que definen el perfil de emprendedor social y analizar las competencias de emprendimiento social del alumnado. En esta línea, un estudio realizado con estudiantes del área de empresariales (García-Hernández, Mendoza, Gutiérrez y Santo, 2017), indica la importancia de adquirir habilidades y competencias de ámbito personal, social y relacionado con la innovación para desarrollar iniciativas empresariales de carácter social. Del mismo modo, Ferrer-Cerveró, et al. (2014), encontraron resultados similares en estudiantes de Pedagogía, Educación social y Trabajo social. Los resultados de este estudio señalan que el alumnado de estas titulaciones también considera que trabaja sus capacidades para emprender en un proyecto o empresa social, dándose incluso a conocer en qué medida se promueven las competencias para el emprendimiento social tales como son la capacidad de liderazgo, las habilidades sociales y comunicativas, la creatividad y la innovación, la responsabilidad y el compromiso social, entre otras. Como se puede apreciar, tanto estudiantes del ámbito empresarial como de educación consideran relevante para su formación el trabajo de las competencias para el emprendimiento social en las asignaturas. Estos resultados contrastan con los obtenidos en este estudio que revela que los estudiantes de la rama de Educación, con respecto a los de Económicas, perciben que trabajan en mayor medida las competencias para el emprendimiento social en las actividades de aula. En concreto, se puede destacar que existen diferencias significativas en competencias como el trabajo en equipo; repartir y coordinar tareas y funciones de manera competente; relacionarse de manera efectiva con otros grupos, colectivos y/o entidades externas a la clase; interpretar emociones y dar feedback a otras personas; comunicarse eficazmente con diferentes personas y en diversas situaciones; o el sentido ético. En todos los casos, las medias son mayores en los estudiantes de Educación en comparación con los de Económicas.

Respecto a la formación de los estudiantes de Ciencias Económicas y Empresariales, Flores, Guzmán y Barroso (2016), señalan que existen diferencias significativas en el tipo de formación que se imparte a grupos de titulaciones que trabajan el emprendimiento y la economía social respecto a titulaciones que están más enfocadas a formar en la economía convencional. Según estos autores, estas diferencias hacían "referencia a aspectos tales como: los valores, la forma de entender el comportamiento de la economía y la importancia que debe tener la Economía Social dentro de ésta, las competencias y habilidades a adquirir por parte de los gestores, etc." (Flores et al., 2016: 108). También, las conclusiones de estos autores coinciden con los de este estudio, al considerar que titulaciones donde se promueve una enseñanza basada en el emprendimiento y la economía social promueven más la cooperación respecto a titulaciones convencionales centradas en una mentalidad más capitalista. Esto puede ser debido, según estos autores, a que 
estas titulaciones más convencionales dedican un porcentaje más bajo en sus planes de estudio a explicar aspectos del emprendimiento y la economía social y su papel en la economía.

De la misma manera, en este estudio se advierte que las titulaciones donde se promueve más el valor social de la economía presentan una clara ventaja respecto al resto de titulaciones convencionales. Esto es debido a que existen más posibilidades de que estos futuros profesionales pongan en práctica comportamiento propios del emprendimiento social, considerando los beneficios que ello conlleva. Todos estos hallazgos, parecen mostrar que titulaciones como Educación pueden orientar más sus contenidos y competencias a aspectos relativos al emprendimiento social, en comparación con los planes de estudio de Ciencias Económicas, que parecer tener más interés en promover competencias, habilidades o valores más orientados al sistema económico convencional. No obstante, para llegar a resultados más concluyentes consideramos necesario replicar el estudio con muestras mayores de docentes y estudiantes para aportar conclusiones más sólidas sobre estos hallazgos.

Respecto al trabajo del fomento de la cultura emprendedora por parte del profesorado, la Ley 14/2013, de 27 de septiembre, de apoyo a los emprendedores y su internacionalización, señala el papel tan importante que tienen las universidades para que lleven a cabo actividades de información, orientación y asesoramiento con el propósito de que los estudiantes se inicien en el emprendimiento. En este sentido, la ley también recoge que "las universidades fomentarán la iniciación de proyectos empresariales, facilitando información y ayuda a los estudiantes, así como promoviendo encuentros con emprendedores". No obstante, encontramos en los resultados del estudio que la dimensión que hace alusión a la puesta en práctica de acciones e iniciativas de emprendimiento social (Dimensión d. Apelación a la acción), considera a las competencias menos trabajadas por el profesorado, siendo las más destacables "que se generen ideas e identifiquen oportunidades emprendedoras" e "iniciar, construir y hacer realidad iniciativas". También, resulta importante resaltar que las competencias de esta dimensión eran las que menos representación tenían en las competencias más valoradas por los estudiantes. Por lo que se desprende de estos resultados, la necesidad de que el profesorado introduzca en sus asignaturas, más iniciativas, actividades y propuestas para trabajar el emprendimiento social como pueden ser el diseño de proyectos empresariales sociales, facilitándoles información y ayuda para su elaboración e implementación, así como promover encuentros con emprendedores sociales. En este sentido, la Dirección General de Empresa e Industria de la Comisión Europea (2012), también subraya algunas de características que deben poseer los docentes emprendedores para favorecer la educación para el emprendimiento:

El profesorado no podrá enseñar a sus estudiantes a ser emprendedores, si ellos mismos no son emprendedores.

El profesorado debe emplear metodología activa y participativa para fomentar en los estudiantes la creatividad y la innovación.

- $\quad$ El trabajo de los valores y las actitudes emprendedoras puede realizarse en todas las asignaturas, o incluso en una asignatura concreta.

- La educación para el emprendimiento es algo más que formar a los estudiantes para crear una propuesta de empresa. Se trata de trabajar 
actitudes, habilidades y conocimientos emprendedores que estimulen al estudiante a transformar las ideas en acción.

En definitiva, López-Cózar y Priede, (2014), resume cuál debe ser el propósito de la Universidad respecto a la enseñanza sobre emprendimiento:

[...] es preciso que la Universidad asuma la responsabilidad de transmitir a nuestros estudiantes que las empresas deben modificar sus actitudes y comportamientos, pero sobre todo, es fundamental fomentar en las aulas el espíritu emprendedor responsable, con el fin de conseguir un tejido empresarial en el que las nuevas iniciativas sean capaces de asegurar su viabilidad económica y, al mismo tiempo, avanzar hacia una mayor integración social, mayor respeto medioambiental y un modelo de crecimiento más coherente y equilibrado (2014:1)

En esta línea, Espíritu et al. (2012), indican que el emprendimiento debe plantearse a los estudiantes como una opción más para su trayectoria profesional, una vez finalicen sus estudios. El diseño y aplicación del RESAU, pone de manifiesto la utilidad y la efectividad de este instrumento para evaluar el grado de adquisición de las competencias en emprendimiento social, así como la implicación del profesorado respecto a su enseñanza. También, este instrumento resulta clave como elemento de reflexión y autoaprendizaje para que el profesorado mejore sus prácticas educativas en lo concerniente al trabajo sobre emprendimiento social en el aula. Como futuras líneas de investigación, se recomienda analizar en profundidad estudios de casos de buenas prácticas en el trabajo por competencias transversales relacionadas con el emprendimiento social. También, se sugieren construir marcos teórico-prácticos desde los datos, así como modelos de aprendizaje por competencias de emprendimiento social. A partir de estas propuestas de trabajo, se favorecería la elaboración de guías de buenas prácticas docentes para trabajar en el aula competencias relacionadas con el emprendimiento social.

\section{Referencias bibliográficas}

Álvarez Sampayo, A. A., González Díaz, J. E., y Vergara Gómez, L. (2016) El emprendimiento en la Fundación Universitaria Tecnológico Comfenalco 2006-2015. Revista Clio America, No 10, Vol. 20, pp. 126-138. DOI:10.21676/23897848.1872.

Blanco, A., Garín, A. y Rodríguez, R. M. (2012) Emprendimiento social: desarrollo de competencias y valores en el marco universitario. En Rodríguez, R.M. (Coord.) Educación en valores en el ámbito universitario. Propuestas y experiencias. Madrid: Narcea, pp. 45-54.

Capella, C., Gil, J., Martí, M. y Ruiz Bernardo, P. (2015) Construcción de un cuestionario para medir el emprendimiento social en Educación Física. Pedagogía Social. Revista Interuniversitaria, $\mathrm{N}^{\circ}$ 28, pp. 169-188. DOI: 10. sE7179/PsRi_2016.28.13.

Dirección General de Industria y de la Pequeña y Mediana Empresa. (2012) El espíritu emprendedor, motor de futuro. Guía del profesor. Madrid: Subdirección General de Información, Documentación y Publicaciones. 
Espíritu, R., González, R. F., y Alcaraz, E. (2012) Desarrollo de competencias emprendedoras: Un análisis explicativo con estudiantes universitarios. Cuadernos de Estudios Empresariales, $\quad \mathrm{N}^{\mathrm{o}} \quad 22, \quad$ pp. 29-53. http://dx.doi.org/10.5209/rev_CESE.2012.v22.44644.

Ferrer Cerveró, V. R., Cabrera Santacana, O., Alegre Beneria, R. M., Montané Lopez, A., Sánchez Valverde, C. y Alaiz Chueca, E. (2014) Social entrepreneur student profile in Social Education, Pedagogy and Social Work degrees at University of Barcelona. Revista d'Innovació $i$ Recerca en Educació, $\mathrm{N}^{\mathrm{o}}$ 7, Vol. 1, pp. 11-29. DOI:10.1344/reire2014.7.1712.

Flores, D., Guzmán, C. y Barroso, M. O. (2016) La formación en economía social. Análisis de la oferta universitaria de posgrado en España. REVESCO. Revista de Estudios Cooperativos, Segundo Cuatrimestre, No 121, pp. 89-113. DOI: 10.5209/rev_REVE.2016.v121.49703.

Gallagher, K., \& Wessels, A. (2011) Emergent Pedagogy and Affect in Collaborative Research: A Metho-Pedagogical Paradigm. Pedagogy, Culture and Society, No 19, Vol. 2, pp. 239-258. DOI:10.1080/14681366.2011.582260.

García Hernández, Y., Mendoza, J., Gutiérrez, G. y Santo, L. E. (2017) Emprendimiento social en estudiantes del área empresarial de una institución de educación superior tecnológica en el Estado de Hidalgo. XVII Congreso Latino-Iberoamericano de Gestión Tecnológica, Ciudad de México, México. Disponible en: http://www.uam.mx/altec2017/pdfs/ALTEC_2017_paper_194.pdf.

García Lira, A., Cantón, L. C. y Torreblanca, A. (2015) Evaluación por competencias de un programa educativo emprendedor universitario. Revista Iberoamericana de Contaduría, Economía y Administración, $\mathrm{N}^{\mathrm{o}}$ 4, Vol. 8. Disponible en https://dialnet.unirioja.es/servlet/articulo?codigo $=5263331$.

Glunk, U., \& Van Gils, A. (2010) Social Entrepreneurship Education: A Holistic Learning Initiative. International Review of Entrepreneurship, № 8, Vol. 2, pp. 113-131.

Guerrero, M., Urbano, D., Ramos, A. R., Ruiz Navarro, J., Neira, I. y Fernández Laviada, A. (2016) Observatorio de Emprendimiento Universitario en España. Edición $2015-$ 2016. Madrid: Crue Universidades Españolas-RedEmprendia-CISE.

Jiao, H. (2011) A conceptual model for social entrepreneurship directed toward social impact on society. Social Enterprise Journal, $\mathrm{N}^{\mathrm{o}}$ 7, Vol. 2, pp. 130-149. DOI: $10.1108 / 17508611111156600$.

Ley 14/2013, de 27 de septiembre, de apoyo a los emprendedores y su internacionalización.

López Cózar, C. y Priede, T. (2014, julio). Una propuesta para acercar al alumnado al emprendimiento responsable y sostenible. XI Jornadas internacionales de innovación universitaria. Villaviciosa de Odón, Madrid, España, pp. 874-881.

Martín López, S., Fernández Guadaño, J., Bel Durán, P. y Lejarriaga Pérez De Las Vacas, G. (2013) Necesidad de medidas para impulsar la creación de las empresas de participación desde los diferentes niveles de enseñanza. CIRIEC-España, Revista de Economía Pública, Social y Cooperativa, № 78 , pp. 71-99.

Mateescu, V. M. (2014) Perspectives on social entrepreneurship in Romania. Journal Modelling the New Europe, № 10, pp. 55-66.

Melián, A., Campos, V. y Sanchis, J. R. (2017) La Educación de Postgrado en Economía Social en la Universidad Española ¿Una Asignatura Pendiente? CIRIEC-España, Revista de Economía Pública, Social y Cooperativa, No 89, pp. 33-5.

Miller, T.L., Wesley, C. L., \& Williams, D. (2012) Educating the minds of caring hearts: Comparing the views of practitioners and educators on the importance of social 
entrepreneurship competencies. Academy of Management Learning \& Education, $\mathrm{N}^{\mathrm{o}} 1$, Vol.3, pp. 349-370. DOI:10.5465/amle.2011.0017.

Mindt, L., \& Rieckmann, M. (2017) Developing competencies for sustainability driven entrepreneurship in higher education: a literature review of teaching and learning methods. Teoría de la Educación. Revista Interuniversitaria, № 29, Vol. 1, pp. 129159. DOI: http://dx.doi.org/10.14201/teoredu2017291129159.

Mitchelmore, S., \& Rowley, J. (2010) Entrepreneurial competencies: a literature review and development agenda. International Journal of Entrepreneurial Behaviour \& Research, $\mathrm{N}^{\mathrm{o}}$ 16, Vol. 2, pp. 92-111. DOI:10.1108/13552551011026995

Peric, J., \& Delic, A. (2014) Social entrepreneurship in Croatia: do regional disparities influence young people's perception of social entrepreneurship as a potential career path? Ekonomski Vjesnik, № 27, Vol. 1, pp. 81-92.

Priede, T., López Cózar, C. y Rodríguez, A. (2014) Análisis del marco económico-jurídico específico para los emprendedores sociales. Un estudio comparado entre diversos países. CIRIEC-España, Revista de Economía Pública, Social y Cooperativa, № 80, pp. $5-28$.

Rojas, G., Quintero, L., Pertuz, V. y Navarro, A. (2016) Estrategias para el fomento de la cultura de emprendimiento universidades de Valledupar, Colombia. Revista de Educación y Desarrollo Social, $N^{o}$ 10, Vol. 1, pp. 38-57. DOI:10.18359/reds.1448

Sáenz, N. y López, A. L. (2015) Las competencias de emprendimiento social, COEMS: aproximación a través de programas de formación universitaria en Iberoamérica, REVESCO. Revista de Estudios Cooperativos, No 119, pp. 159-182. DOI: 10.5209/rev_REVE.2015.n119.49066.

Salinas, F. y Osorio, L. (2012) Emprendimiento y Economía Social, oportunidades y efectos en una sociedad en transformación. CIRIEC-España, Revista de Economía Pública, Social y Cooperativa, № 75, pp. 129-151.

Sánchez, J. C., Ward, A., Hernández, B. y Florez, J. (2017) Educación emprendedora: Estado del arte. Propósitos y Representaciones, $\mathrm{N}^{\mathrm{o}}$ 5, Vol. 2, pp. 401-473. DOI: 10.20511/pyr2017.v5n2.190.

Seguí Mas, E., Tormo Carbó, G., Sarrión Viñes, F. y Julià Igual, J. F. (2014) La Economía Social y la Universidad Emprendedora: Transferir, Emprender y Cooperar en Acción. Instituto de Estadística y Cartografía de Andalucía. Consejería de Economía, Innovación, Ciencia y Empleo.

Sigüenza, C. A., Macías, B. C. y Serrano, B. J. (2016) El Emprendimiento Como Base En La Condición Socioeconómica. INNOVA Research Journal, № 1, Vol. 12, pp. 1-10.

Sinha, P. K., Pathak, B. y Thomas, S. (2014) Teaching Social Entrepreneurship: Development through the Juxtaposition of Heart and Head. Indian Journal of Economics and Business, № 13, Vol. 3, pp. 331-339.

UNESCO (2009) World Conference on Higher Education: The New Dynamics of Higher Education and Research for Societal Change and Development. Communiqué Declaration. Paris, France. Disponible http://unesdoc.unesco.org/images/0018/001832/183277e.pdf.

Viloria, H. (2017) Desarrollo de competencias emprendedoras en docentes de universidades públicas autónomas. Revista Encuentros, No 15, Vol. 1, pp. 133-146. DOI:10.15665/re.v15i1.815.

Wronka-Pospiech, M. (2016) The identification of skills and competencies for effective management in social enterprises. A managerial perspective. Management, $\mathrm{N}^{\mathrm{o}} 20$, Vol. 1, pp. 40-57. DOI: 10.1515/manment-2015-0023. 